\title{
Application of ultrastructural morphometry to lung biopsy specimens in pulmonary histiocytosis $\mathrm{X}$
}

\author{
M A T THEW B. D I VERTIE, STA N LEY M. CASSA N ${ }^{1}$, \\ a n d A R OLD L. B R O W N, J r. \\ Mayo Clinic and Mayo Foundation, Rochester, Minnesota 55901, USA
}

\begin{abstract}
Divertie, M. B., Cassan, S. M., and Brown, A. L., Jr. (1975). Thorax, 30, 326-332. Application of ultrastructural morphometry to lung biopsy specimens in pulmonary histiocytosis X. Stereological techniques were applied to an electron microscopic study of biopsy samples from nine human lungs with diffuse pulmonary histiocytosis $\mathrm{X}$, and the results were compared with values for normal lungs. This made possible a morphometric analysis of the tissue changes associated with the measurable abnormalities in gas transfer present in this disease. The small increases in arithmetic mean thickness of the alveolar-capillary membranes appeared insufficient to account for the reduction in gas transfer present. When compared with normal lung, a threefold increase in volumetric fraction of septal intercapillary tissue was found along with a corresponding decrease in septal capillaries. While uniformity of distribution cannot be determined by this method, it appears that abnormalities of blood gas transfer in this disease result primarily from a decrease in the available diffusing surface and the ventilation-perfusion disturbances with which these tissue changes are associated.
\end{abstract}

\begin{abstract}
Abnormalities of carbon monoxide diffusing capacity in patients with diffuse interstitial lung disease at first were thought to be due mainly to an increase in the membrane component of diffusion as a result of anatomical thickening of the blood-air barrier (alveolar-capillary membrane) (Austrian et al., 1951). While inferential evidence has accumulated that other factors may be more important (Finley, Swenson, and Comroe, 1962; Hamer, 1964), the width of this structure could not be directly measured until recently since its components are not adequately visualized by light microscopy (Divertie and Brown, 1964). Irregularly distributed tissue changes present in alveolar septa in interstitial pneumonitis and fibrosis have been considered significant in the disturbed physiology of these patients by producing loss of vascular bed and diffusion surface and interfering with the normal relationship of ventilation and perfusion. An accurate quantitative determination of these interstitial tissue changes would be valuable in clarifying the individual contribution of these factors to abnormal blood-air gas exchange in these and similar diseases. This can be accom-

1Present address: Center for Health Sciences, Los Angeles, California 90024
\end{abstract}

plished by applying stereological techniques electron microscopic sections of lung tissue as originally described by Weibel (1963a). In the present study we have extended this method to the evaluation of biopsy specimens of normal an diseased lungs and employ it to compare th results for normal lung tissue with measurements obtained from biopsy material from the lungs of patients with histiocytosis $\mathrm{X}$.

\section{METHODS}

Lung tissue from seven patients with primarf̂ु pulmonary histiocytosis $\mathrm{X}$ was obtained at this time of open lung biopsy performed in each case for the purpose of histological diagnosis (Fig. 1.9 Criteria for this diagnosis were those commonl accepted (Auld, 1957; Lewis, 1971). With the exception of one patient, the results of pulmonar $\$$ function studies performed by standard techniques (Cournand et al., 1941; Baldwin, Cournando and Richards, 1948; Wood and Geraci, 1949 Bateman, 1950; Bates, Boucot, and Dormer, 195 Leuallen and Fowler, 1955) were compatible with reduced lung volumes and impaired carbon mop oxide diffusing capacity in the absence of airwas 


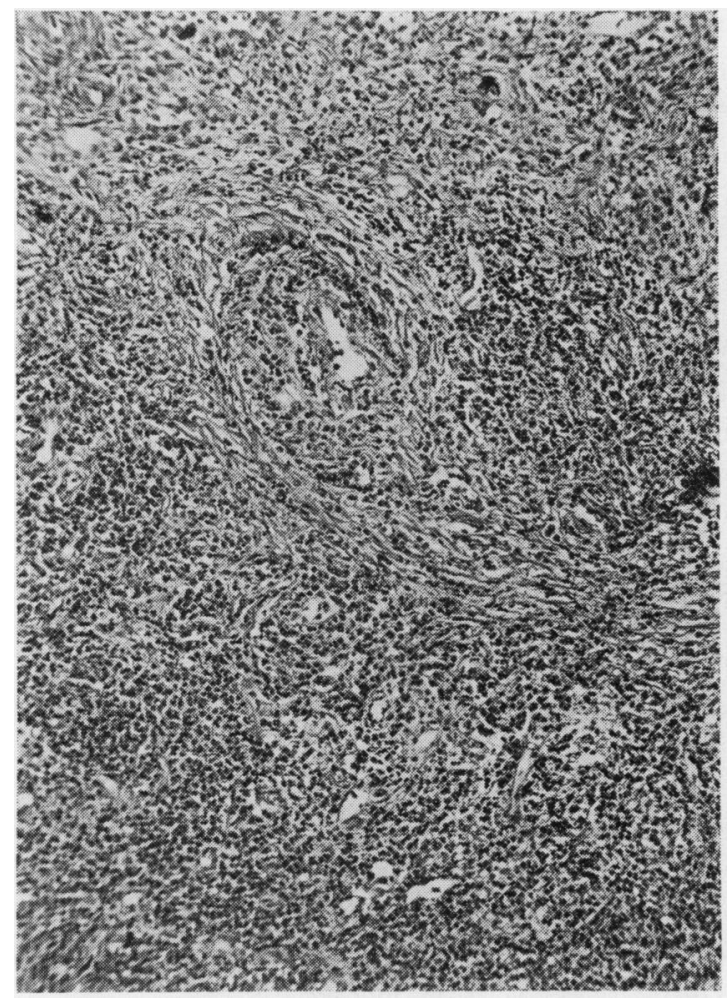

FIG. 1. Pulmonary granuloma in histiocytosis $X$. The majority of the cells are histiocytes with a sprinkling of eosinophils. Collagen proliferation, particularly in the top central portion of the photomicrograph, is apparent (Haematoxylin and eosin $\times 100$ ).

obstruction (Table I). In the remaining patient there was evidence of obstructive disease of the airways with reduced dynamic lung volumes. Normal lung tissue previously described and included here for comparative purposes was obtained from a further nine patients at the time of resection of solitary circumscribed pulmonary tumours and

T A B L E I

CLINICAL AND SELECTED PHYSIOLOGICAL DATA FROM 7 PATIENTS WITH PRIMARY PULMONARY HISTIOCYTOSIS X

\begin{tabular}{|c|c|c|}
\hline & Mean & Range \\
\hline \multirow{4}{*}{$\begin{array}{l}\text { Age (yr) } \\
\text { Duration of illness (yr) } \\
\text { Total lung capacity, } 1 \\
\% \text { of predicted normal } \\
\text { Steady state carbon monoxide diffusing } \\
\text { capacity, \% of predicted normal } \\
\text { Maximal midexpiratory }{ }^{1} \\
\text { flow rate, \% of predicted normal }\end{array}$} & 40 & $\begin{array}{c}25-57 \\
0 \cdot 7-1 \cdot 5\end{array}$ \\
\hline & 70 & $50-87$ \\
\hline & 56 & $36-73$ \\
\hline & 83 & 27-139 \\
\hline
\end{tabular}

1 One patient had an MMF $27 \%$ of predicted normal with normal residual volume and functional residual capacity. was taken from lung tissue remote from the lesion itself (Cassan, Divertie, and Brown, 1974). Specimens were obtained from the randomly arranged respiratory portion of the lung, only excluding the immediately subpleural zone.

The methods used for tissue fixation and examination by electron microscopy, and the applications of morphometric principles to the analysis of tissue specimens, were based on the work of others (Dalton, 1955; Watson, 1958; Luft, 1961; Sabatini, Bensch, and Barrnett, 1963; Weibel, 1963b; Venable and Coggeshall, 1965; Weibel, Kistler, and Scherle, 1966) and have been described by us previously (Cassan et al., 1974). For each patient, 20 electron micrographs were prepared at a magnification of $\times 2200$ by randomly selecting tissue sections and photographic fields as described by Weibel (1963a). Each micrograph was enlarged to match a translucent test pattern of 168 points and 84 lines on which point-counting volumetry was applied to air spaces, capillaries, and the components of alveolar septal tissue (Figs 2 and 3). Fractional air space and fractional capillary space were determined by this method, and surface area of alveoli and capillaries was calculated as previously described elsewhere. Septal tissue was divided into intercapillary tissue (ICT) and alveolar capillary tissue (ACT) by lines drawn perpendicular to the alveolar epithelial surface at the lateral extremities of the capillaries (Fig. 4). This arbitrary division of tissue components was used to separate that portion of alveolar septal tissue directly related to gas exchange from that which was not, thereby allowing an assignment of a numerical value to each. Such a value provides a basis for comparision of normal with diseased states in which an impairment of diffusion is known to be present. The relationship of ACT to ICT not only affords an index of the proportions of each in the septa studied but its value is independent of the degree of lung inflation present.

Arithmetic mean thickness (AMT) of blood-air barrier was calculated by relating tissue volume to capillary surface alone as recommended by Weibel (1963a) for consideration of diffusing problems. Harmonic mean thickness (HMT) of this structure was derived by a method independent of relative tissue volume using the calculation from harmonic mean intercept lengths. Correction factors for fixation and processing and actual degree of lung inflation were not considered pertinent for comparative purposes, because of the manner in which lung tissue was obtained and because tissues obtained from normal and abnormal lungs were 


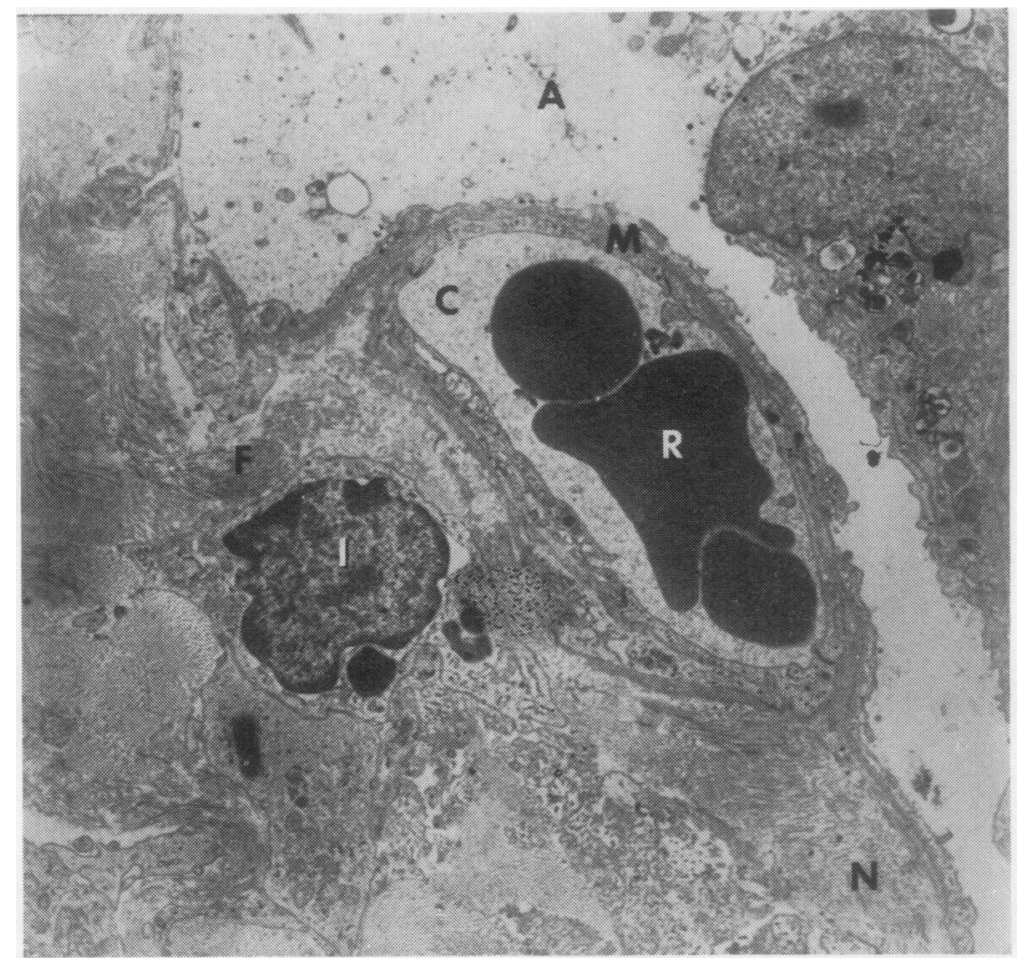

FIG. 2. Alveolocapillary membrane in histiocytosis X. A portion of the membrane $(M)$ is of normal thickness. A fibroblast (I) with associated collagen $(F)$ lies between the capillary $(C)$ and an air space out of the field to the left. More mature collagen $(N)$ has become deposited beneath the basement membrane of an alveolar lining cell. An erythrocyte $(R)$ and an air space $(A)$ with an alveolar macrophage are also present $(\times 4,500)$.

identically treated and processed. Lung volumes used in the calculation of surface areas were those of the respiratory portion of the lung determined from predicted total lung capacity based on sex and height. Mean values and standard deviations were obtained for all parameters.

\section{RESULTS}

FRACTIONAL VOLUMES (Table II) In normal lungs the fractional air space comprised $44.4 \%$ of total respiratory volume. Mean values for fractional capillary space and total tissue volume were $18.5 \%$ and $37.1 \%$ respectively, the latter being composed in the alveolar septa of $21.2 \%$ alveolar capillary tissue and $15.9 \%$ intercapillary tissue as previously defined. In the lungs of patients with histiocytosis $\mathrm{X}$ the mean fractional air space was reduced to $28.9 \%$ of total volume or about twothirds that for normal lungs. There was also a $50 \%$ reduction in fractional capillary space to
$8.9 \%$ of the whole. Alveolar-capillary tissue volume was only slightly reduced from $21.2 \%$ i normal lungs to $17.4 \%$ in the present series. Intero capillary tissue volume increased to $44.8 \%$ or three times normal values, showing that the bulk of additional tissue in pulmonary histiocytosis is deposited preferentially between septal capile. laries and not in the alveolar-capillary membraneso This distribution of abnormal tissue in intercapir lary sites was substantiated by a marked reduction in the ACT/ICT ratio which fell from 1.33:1 ifo normal lungs to $0 \cdot 39: 1$ in diseased lungs, a value which is not influenced by the degree of lune inflation.

SURFACE AREA (Table III) The mean surface areas of alveoli and capillaries in normal lung® were $953 \mathrm{~m}^{2}$ and $769 \mathrm{~m}^{2}$ respectively, approxi mately ten times previously derived values. The discrepancy is compatible with values calculate $\mathbb{}$ on the basis of predicted lung volumes in the 


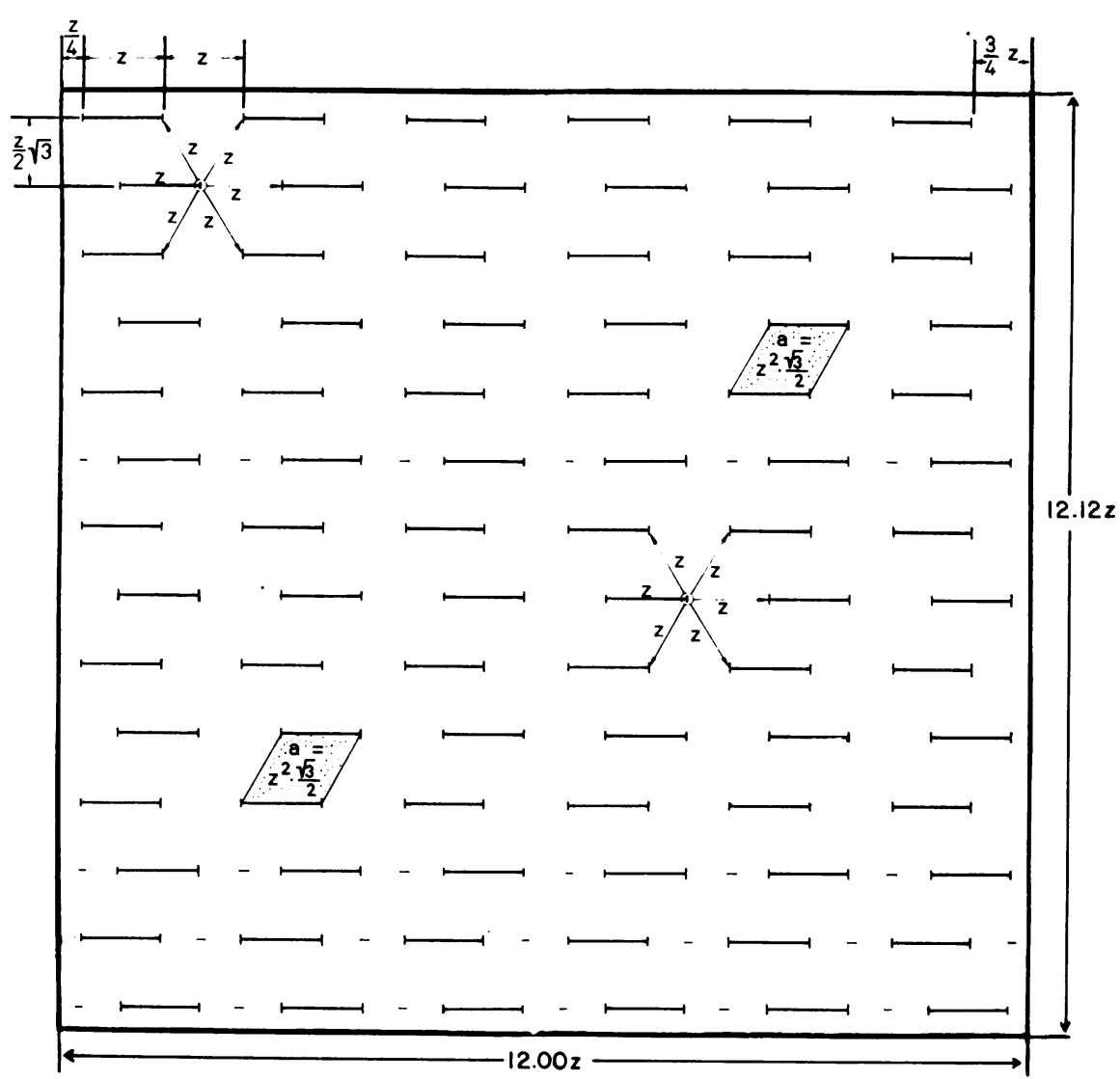

FIG. 3. Test pattern grid for superimposition on photographs (84 lines connecting 168 equidistant points) (from Weibel et al. (1966) by permission of The Rockefeller University Press).

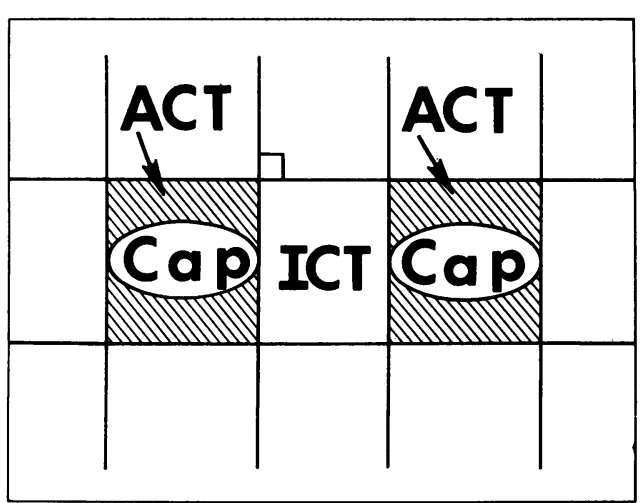

FIG. 4. Diagram of alveolar tissue subdivided by lines perpendicular to alveolar surface at lateral extremes of capillaries. ACT =alveolar-capillary tissue; ICT = intercapillary tissue; Cap=capillary (from Cassan et al. (1974) by permission of the American College of Chest Physicians).
T A B L E I I

FRACTIONAL VOLUMES

\begin{tabular}{|c|c|c|c|c|}
\hline & \multicolumn{2}{|c|}{ Normal } & \multicolumn{2}{|c|}{ Histiocytosis X } \\
\hline & Mean & $1 \mathrm{SD}$ & Mean & $1 \mathrm{SD}$ \\
\hline $\begin{array}{l}\text { Air space \% } \\
\text { Capillary space \% } \\
\text { ACT \%1 } \\
\text { ICT \%2 } \\
\text { ACT } / \text { ICT }\end{array}$ & $\begin{array}{l}44 \cdot 4 \\
18 \cdot 5 \\
21 \cdot 2 \\
15 \cdot 9 \\
1 \cdot 33\end{array}$ & $\begin{array}{l} \pm 3 \cdot 25 \\
\pm 2.00 \\
\pm 1 \cdot 12 \\
\pm 1.94 \\
\pm 0.19\end{array}$ & $\begin{array}{r}28 \cdot 9 \\
8 \cdot 9 \\
17 \cdot 4 \\
44 \cdot 8 \\
0 \cdot 39\end{array}$ & $\begin{array}{l} \pm 2.96 \\
\pm 1.34 \\
\pm 3.67 \\
\pm 3.75 \\
\pm 0.11\end{array}$ \\
\hline
\end{tabular}

${ }^{1}$ Septal alveolar capillary tissue.

2 Septal intercapillary tissue.

presence of diminished lung inflation as previously described. In diseased lungs, the mean alveolar surface area was reduced to $446 \mathrm{~m}^{2}$ or $46.8 \%$ of the normal value. Mean capillary surface area was $372 \mathrm{~m}^{2}$ in lungs with histiocytosis $\mathrm{X}$ or $48.3 \%$ of normal values.

THICKNESS OF ALVEOLAR-CAPILLARY MEMBRANE (Table IV) The arithmetic mean thickness of the 
T A B L E I I I

SURFACE AREAS (SQUARE METRES)

\begin{tabular}{|c|c|c|c|c|}
\hline & \multicolumn{2}{|c|}{ Normal } & \multicolumn{2}{|c|}{ Histiocytosis $\mathrm{X}$} \\
\hline & Mean & $1 \mathrm{SD}$ & Mean & $1 \mathrm{SD}$ \\
\hline $\begin{array}{l}\text { Alveoli (A) } \\
\text { Capillaries (C) } \\
\text { Ratio: A/C }\end{array}$ & $\begin{array}{l}953 \\
769 \\
1 \cdot 31\end{array}$ & $\begin{array}{r} \pm 52.76 \\
\pm 76.88 \\
\pm 0.10\end{array}$ & $\begin{array}{l}446 \\
372 \\
1 \cdot 27\end{array}$ & $\begin{array}{r} \pm 79 \cdot 08 \\
\pm 68.46 \\
\pm 0.16\end{array}$ \\
\hline
\end{tabular}

T A B L E I V MEAN ALVEOLAR-CAPILLARY MEMBRANE THICKNESS

\begin{tabular}{|c|c|c|c|c|}
\hline & \multicolumn{2}{|c|}{ Normal } & \multicolumn{2}{|c|}{ Histiocytosis $\mathrm{X}$} \\
\hline & Mean & $1 \mathrm{SD}$ & Mean & $1 \mathrm{SD}$ \\
\hline $\begin{array}{l}\text { Arithmetic } \\
\text { Harmonic }\end{array}$ & $\begin{array}{l}1.665 \\
0.829\end{array}$ & $\begin{array}{l} \pm 0.128 \\
\pm 0.067\end{array}$ & $\begin{array}{l}2.853 \\
1.035\end{array}$ & $\begin{array}{l} \pm 0.401 \\
\pm 0.045\end{array}$ \\
\hline
\end{tabular}

alveolar-capillary membranes had an average value of 1.665 microns in normal lungs which closely approximates previously estimated values. This was increased to 2.853 microns in pulmonary histiocytosis $\mathrm{X}$ or about 1.7 times normal. Harmonic mean thickness, which has been shown to relate more directly to diffusion of gases, had a mean value in normal lungs of 0.829 microns. In the diseased lungs studied, this was increased by a factor of 1.2 to 1.035 microns.

\section{DISCUSSION}

The disease which Hand described more than 75 years ago is still poorly understood (Hand, 1893). It has been defined as a non-neoplastic proliferative disorder of histiocytes of unknown aetiology with variably widespread distribution in the body. Lichtenstein (1953) introduced the term histiocytosis $\mathrm{X}$ to emphasize the predominant pathological feature of histiocytic proliferation and its unknown cause. The primary pulmonary form of this disease is generally considered to be a relatively benign condition with remissions more common than progression.

The widely disseminated pulmonary lesions are characterized by the presence of histiocytes and eosinophils accompanied by the formation of granulomas which are replaced in some instances by interstitial fibrosis. In this and other diffuse pulmonary diseases, general acceptance of the value of diagnostic lung biopsy implies that the abnormalities present in the tissue sample obtained are representative of widespread changes throughout the lung. These are responsible for significant abnormalities in pulmonary function and in the radiographic appearance of the chest.
While the distribution of pathological changes cannot be determined from a biopsy specimen, ip is apparent from the extent and severity of disturo bances of form and function that major portions of lung parenchyma are involved. The presen $\mathbb{B}$ group of patients conforms to the physiologican pattern of restrictive lung disease in which small lung volumes and reduced diffusing capacity are unaccompanied by evidence of airway obstruction $\vec{\omega}$ In one patient there was also evidence of ventila tory obstruction, as has been described by others in advanced stages of the disease (Hoffman, Cohn and Gaensler, 1962).

A substantial reserve for diffusion exists in the blood-air barrier, and theoretical considerations have indicated that a measurable increment in the normal alveolar-arterial oxygen tension gradient

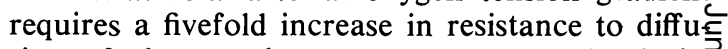
sion of the membrane component ( $\left.D_{M}\right)$ of thed diffusing capacity (Staub, 1963). Alveolar-arteriato oxygen tension gradients may remain significantles abnormal while breathing $100 \%$ oxygen and are interpreted as due to ventilation/perfusion abnoro malities. In the present study, the arithmetic mean thickness of the blood-air barrier was obtained bu relating tissue volume to capillary surface only? a method preferred when diffusion problems are being considered (Weibel, 1971). Morphologicallỵ the tissues of this structure appeared normal and the measurements obtained were similar to thos previously determined for human lung free of. disease. Harmonic mean thickness has been shown to relate more directly to diffusion of gases anci is determined by a method independent of point counting volumetry and surface intersection Consequently, it does not involve arbitrary sub: divisions of septal tissue. Its value also was withing normal limits and the ratio of AMT to HMT was approximately $2: 1$, which is similar to what has been reported in the normal lungs of a number of mammalian species (Cassan et al., 1974). The ratio reflects an optimal functional relationshirs between structural integrity and gas permeabilitwo in the blood-air barrier which appears to be inde pendent of the degree of lung inflation. These results do not support the concept of thickening of this structure as a significant impediment t? gas transfer in this disease.

Measurements of the thickness of the blood-ait? barrier do not require a calculation of total lungo capacity, and morphometric derivation of fracti tional volumes of air space and capillary anc tissue volumes can be made without knowledge of lung size. Using this method, reductions in mean fractional air space and capillary space were 
found to be present in patients with histiocytosis $\mathrm{X}$ when compared with values for normal lungs and were more marked for blood vessels than for alveoli. Accompanying a 50\% reduction in capillary volume there was an almost threefold increase in tissue volume, indicating that the encroachment on air space is due to replacement by noncapillary tissue which is incapable of taking part in the diffusion process. The relative proportions of alveolar septal structures which are involved in bloodair gas transfer can also be compared in the absence of absolute values with those which do not participate in this function (Weibel, 1963a). In this way it became apparent (Fig. 2) that the proportion of intercapillary tissue in these patients increased to three times the value found in normal alveolar septa.

This preferential distribution of cells and connective tissue in these sites was substantiated by a marked reduction in the ratio of alveolar-capillary tissue to intercapillary tissue (ACT/ICT) from $1.33: 1$ in normal septa to $0.39: 1$ in the present study, a number which is independent of the degree of lung compression or inflation. The calculation of mean surface area of alveoli and capillaries depended on the use of predicted values for total lung capacity based on the sex and height of the individual. While the absolute results obtained may reasonably be expected to contain some mathematical variation, there was no doubt of the trend which emerged since the surface areas of both blood vessels and air spaces in diseased lungs were less than half those for normal lungs, indicating a marked reduction in total diffusing surface.

The arbitrarily derived value for septal alveolarcapillary tissue (ACT) contains both alveolarcapillary membranes, which were of normal width in these patients, and the surviving capillaries whose walls form part of the blood-air barrier. In view of the demonstrated reduction in capillary surface area and fractional capillary volume, it seems reasonable to conclude that the reduced ratio of ACT to ICT in septal tissue is not wholly due to an increase in the latter but most probably reflects loss of functioning capillaries as well.

Within the limits of the sampling method, the present study lends support to the role of factors other than thickening of the alveolar-capillary membrane in the production of measurable abnormalities of diffusing capacity in pulmonary histiocytosis $X$. In the main, the abnormalities observed were an increase in the intercapillary tissue of alveolar septa and a reduction in alveolar and capillary surface areas. The preferential accumulation of tissue in intercapillary regions with relative sparing of the blood-air barrier is reflected in the limited increase in the thickness of this structure. This increase in intercapillary septal tissue may be expected to result in reduced and uneven lung compliance and nonuniform regional ventilation. It can be reasonably assumed that each contributes to a profound disturbance of the normal relationship of regional ventilation and perfusion in the lung.

The measurable reduction in alveolar and capillary surface areas in diseased lungs is in agreement with previous descriptions of the pathology of this disease (Gracey, Divertie, and Brown, 1971) but adds a quantitative factor not previously available. In addition to resulting in a diminished diffusing surface, reduction of the pulmonary capillary bed may be associated with a more rapid transit time of pulmonary capillary blood through it so that oxygen uptake is impaired, particularly during exercise. Based on the mathematical predictions of others that measurable reduction in the diffusion of oxygen across the alveolar-capillary membrane requires an increase in membrane thickness of more than five times its normal width (Staub, 1963), the degree of thickening of the blood-air barrier demonstrated in this study appears unable of itself to interfere significantly with gas transfer. However, it is theoretically conceivable that such thickening may become significant in the presence of grossly abnormal ventilation-perfusion relationships and reduced erythrocyte transit time (Luchsinger, Moser, Bühlmann, and Rossier, 1957). In these extreme circumstances, interference with gas transfer would be due to a combination of interrelated and complementary variables. These results and conclusions are similar to those we have previously reported for other diffuse interstitial lung diseases.

\section{REFERENCES}

Auld, D. (1957). Pathology of eosinophilic granuloma of the lung. Archives of Pathology, 63, 113.

Austrian, R., McClement, J. H., Renzetti, A. D., Jr., Donald, K. W., Riley, R. L., and Cournand, A. (1951). Clinical and physiologic features of some types of pulmonary diseases with impairment of alveolar-capillary diffusion: the syndrome of "alveolar capillary block". American Journal of Medicine, 11, 667.

Baldwin, E. DeF., Cournand, A., and Richards, D. W., Jr. (1948). Pulmonary insufficiency. I. Physiological classification, clinical methods of analysis, standard values in normal subjects. Medicine, 27, 243. 
Bateman, J. B. (1950). Studies of lung capacities and intrapulmonary mixing: normal lung capacities. Journal of Applied Physiology, 3, 133.

Bates, D. V., Boucot, N. G., and Dormer, A. E. (1955). The pulmonary diffusing capacity in normal subjects. Journal of Physiology, 129, 237.

Cassan, S. M., Divertie, M. B., and Brown, A. L., Jr. (1974). Fine structural morphometry on biopsy specimens of human lung. I. Normal lung. Chest, 65, 269.

Cournand, A., Baldwin, E. DeF., Darling, R. C., and Richards, D. W., Jr. (1941). Studies on intrapulmonary mixture of gases. IV. The significance of the pulmonary emptying rate and a simplified open circuit measurement of residual air. Journal of Clinical Investigation, 20, 681.

Dalton, A. J. (1955). A Chrome-osmium fixative for electron microscopy (abstract). Anatomical Record, 121, 281.

Divertie, M. B. and Brown, A. L., Jr. (1964). The fine structure of the normal human alveolocapillary membrane. Journal of the American Medical Association, 187, 938.

Finley, T. N., Swenson, E. W., and Comroe, J. H., Jr. (1962). The cause of arterial hypoxemia at rest in patients with "alveolar-capillary block syndrome". Journal of Clinical Investigation, 41, 618 .

Gracey, D. R., Divertie, M. B., and Brown, A. L., Jr. (1971). Primary pulmonary histiocytosis X: electron microscopic study in eight cases. Chest, $59,5$.

Hamer, J. (1964). Cause of low arterial oxygen saturation in pulmonary fibrosis. Thorax, 19, 507.

Hand, A., Jr. (1893). Polyuria and tuberculosis. Archives of Pediatrics, 10, 673.

Hoffman, L., Cohn, J. E., and Gaensler, E. A. (1962). Respiratory abnormalities in eosinophilic granuloma of the lung: long-term study of five cases. New England Journal of Medicine, 267, 577.

Leuallen, E. C. and Fowler, W. S. (1955). Maximal midexpiratory flow. American Review of Tuberculosis and Pulmonary Diseases, 72, 783.

Lewis, J. G. (1971). Pulmonary manifestations of histiocytosis X. Proceedings of The Royal Society of Medicine, 64, 338.

Lichtenstein, L. (1953). Histiocytosis X: integration of eosinophilic granuloma of bone, "Letterer-
Siwe disease" and "Schüller-Christian disease $\overrightarrow{\overline{3}}$ as related manifestations of a single nosologit entity. Archives of Pathology, 56, 84.

Luchsinger, P. C., Moser, K. M., Bühlmann, A., ar Rossier, P. H. (1957). The interrelationship be tween cor pulmonale capillary bed restriction and diffusion insufficiency for oxygen in the lung. American Heart Journal, 54, 106.

Luft, J. H. (1961). Improvements in epoxy resin en $\vec{P}$ bedding methods. Journal of Biophysical and Biochemical Cytology, 9, 409.

Sabatini, D. D., Bensch, K., and Barrnett, R. (1963). Cytochemistry and electron microscopyx. the preservation of cellular ultrastructure arfof enzymatic activity by aldehyde fixation. Journg of Cell Biology, 17, 19.

Staub, N. C. (1963). Alveolar-arterial oxygen tensid gradient due to diffusion. Journal of Applied Physiology, 18, 673.

Venable, J. H. and Coggeshall, R. (1965). A simp $\overrightarrow{\mathrm{i}-}$ fied lead citrate stain for use in electron microf copy. Journal of Cell Biology, 25, 407.

Watson, M. L. (1958). Staining of tissue sections $f \overrightarrow{A B}$ electron microscopy with heavy metals. Journgt of Biophysical and Biochemical Cytology, 475.

Weibel, E. R. (1963a). Morphometry of the Humas Lung. Academic Press, New York. (1963b). Principles and methods for the mos phometric study of the lung and other organis. Laboratory Investigation, 12, 131. (1971). Morphometric estimation of pulmona讘 diffusion capacity. I. Model and method. Respiration Physiology, 11, 54.

Kistler, G. S., and Scherle, W. F. (1966). Practical stereological methods for morpho metric cytology. Journal of Cell Biology, 30, 230

Wood, E. H. and Geraci, J. E. (1949). Photoelectrị determination of arterial oxygen saturation man. Journal of Laboratory and Clinic Medicine, 34, 387.

Requests for reprints to: Dr. Matthew B. Divertie Mayo Clinic and Mayo Foundation, Rochester, Mir. nesota, 55901 USA. 